\title{
Animal-Visitor Interactions and the Visitor Experience: Visitor Behaviors, Attitudes, Perceptions, and Learning in the Modern Zoo
}

\author{
Mark James Learmonth", ${ }^{1,}$, Samantha J. Chiew ${ }^{1}$, Andrea Godinez ${ }^{2}$, and Eduardo J. Fernandez ${ }^{3}$ \\ ${ }^{1}$ Animal Welfare Science Centre, Faculty of Veterinary and Agricultural Sciences, \\ The University of Melbourne \\ ${ }^{2}$ Burke Museum of Natural History and Culture, The University of Washington \\ ${ }^{3}$ School of Animal and Veterinary Sciences, The University of Adelaide \\ *Corresponding author (Email: markjameslearmonth@gmail.com) \\ ORCID: MJL: https://orcid.org/0000-0002-2237-0665, SJC https://orcid.org/0000-0003-2514-1136, \\ AG https://orcid.org/0000-0003-3660-276X, EJF: https://orcid.org/0000-0001-5444-6604
}

Citation - Learmonth, M. J., Chiew, S. J., Godinez, A., \& Fernandez, E. J. (2021). Animal-visitor interactions and the visitor experience: Visitor behaviors, attitudes, perceptions, and learning in the modern zoo. Animal Behavior and Cognition, 8(4), 632-649. https://doi.org/10.26451/abc.08.04.13.2021

\begin{abstract}
Animal-Visitor Interactions (AVIs) have become commonplace in zoological institutions and facilities globally. However, most AVI research focuses on the effects of visitors on the welfare of animals, with considerably fewer studies examining the visitor experience itself. Furthermore, robust evaluations of the efficacy of zoo education programs and engagements for increasing visitor awareness of conservation issues, and for fostering longterm pro-conservation behavior changes in them, are under-researched. This paper reviews the current literature that pertains to the effects of zoo visitation and AVIs on visitor perceptions, beliefs, and attitudes. We briefly note some of the known effects that zoo visitors have on zoo animals, then explore the effects that factors such as enclosure design, animal visibility and behaviors, and AVIs can have on visitors' overall experience whilst attending the zoo. We suggest that future research needs to more closely examine the relationships and interactions between zoo visitors and zoo animals; why some zoo visitors over others repeat visitation; what the differences in beliefs and attitudes may be between "zoo visitors" and "non-zoo visitors" (i.e., other general public); and to make a concerted effort to understand: (1) what visitors do after they leave the zoo, and (2) whether visitors adopt long-term proconservation behaviors into their daily lives. We further suggest that future research needs to start investigating indirect measures related to the visitor experience, such as: (a) individual conservation support outside of the zoo; (b) internet activity; (c) changes in sustainable purchasing practices related to knowledge gains; (d) financial investment in sustainable or ethical companies after knowledge gains; (e) and the longitudinal effects of zoo visits.
\end{abstract}

Keywords - Animal-visitor interactions, Human-animal interactions, Visitor attitudes, Visitor behaviors, Visitor experience, Visitor learning, Visitor perceptions

Conservative estimations of annual visitation have indicated that zoos and aquariums, globally, receive at least 700 million visitors every year (Gusset \& Dick, 2011; Moss et al., 2014). Historically, zoos were viewed as a leisure activity - venues primarily attended for human awe and entertainment (Carr \& Cohen, 2011; Gray, 2017; Reading \& Miller, 2007; Tribe \& Booth, 2003). Many modern zoos have attempted to pivot from this, to instead be seen as educational and conservation-focused institutions, and 
many visitors have indeed reported viewing zoos as educational destinations (Briseño-Garzón et al., 2007; Falk et al., 2008; Packer \& Ballantyne, 2002). However, entertainment may still be one of the most common drivers for zoo and aquarium visitation by the public (Roe \& McConney, 2015). Animal-Visitor Interactions (AVIs) are quite common in zoological institutions and facilities globally, yet critical examination and evaluation of their impacts (upon both animals and visitors) are conspicuously absent, or are at least underreported (D'Cruze et al., 2019). Nonetheless, the rate of publication of new research and literature examining the effects that zoo visitors may have upon zoo animals is quickly increasing (Binding, et al., 2020; Sherwen et al., 2018; Sherwen \& Hemsworth, 2019).

The effects of zoo visitors on zoo animals are now well documented, ranging from highly negative, to innocuous, to positive experiences (Claxton, 2011; Collins et al., 2016; Davey, 2007a; D'Cruze et al., 2019; Fernandez et al., 2009, 2021; Jones et al., 2016; Kreger \& Mench, 1995; Mitchell et al., 1992; Sherwen \& Hemsworth, 2019). Some examples of factors that influence animal responses to visitors have included visitor noise-level, proximity, and presence versus absence of visitors (Carder \& Semple, 2008; Chiew, Butler et al., 2019; Chiew et al., 2020, 2021; Larsen et al., 2014; Learmonth et al., 2018; Sherwen, Harvey et al., 2015; Sherwen, Hemsworth et al., 2015; Sherwen, Magrath et al., 2015). Additionally, these visitor effects on zoo animals have been examined through both the behavioral responses of the animals and through physiological responses, such as the sampling of glucocorticoid concentrations through non-invasive fecal glucocorticoid metabolites (FGM; Chiew, Butler et al., 2019; Chiew et al., 2021; Fanson \& Wielebnowski, 2013; Keay et al., 2006; Pifarré et al., 2012; Kuhar, 2008; Sellinger \& Ha, 2005; Sherwen et al., 2014; Sherwen \& Fanson, 2015; Sherwen, Harvey et al., 2015; Sherwen, Magrath et al., 2015). For a recent review of the visitor effects on zoo animals, see Sherwen and Hemsworth (2019).

An area of inquiry that is still considerably lacking in the scientific literature, though, is that of the effects that zoo visits - and, in particular, viewing of (or encounters with) zoo animals during those visits - have on the zoo visitors. On top of this, there have been almost no studies that have compared beliefs, attitudes and knowledge of zoo practices between zoo visitors and non-zoo visitors (Fernandez, 2019; Godinez \& Fernandez, 2019). The main limitation for performing these kinds of comparative studies is the high degree of difficulty in recruiting sufficient suitable candidates, especially in the nonzoo visitor group. However, there is now a moderate amount of published literature in education-related fields that has explored the efficacy of zoos' educational and/or advocacy programs on both short and long-term conservation-related learning outcomes in zoo visitors that is of importance here (Collins et al., 2016; 2019; 2020a; 2020b; Falk et al., 2007; Hayward \& Rothenberg, 2004; Jensen, 2014a; Jensen et al., 2017; Lindemann-Matthies \& Kamer, 2005; Moss \& Esson, 2010; Moss et al., 2015, 2017a, b; Skibins \& Powell, 2013; Spooner et al., 2019; Spooner, Jensen et al., 2021).

This review shall explore the modest amount of AVI research that has been conducted in fields such as ethology, animal welfare, visitor studies, education, and psychology, exploring a few key examples of the known effects visiting a zoo has on the zoo visitor. We initially note what is known about the "visitor effect," or what effect visitors have on the behaviors and overall welfare of zoo animals. However, much of the paper will focus specifically on the effects that visiting zoos generally and AVIs specifically have on the zoo visitor. For instance, we examine aspects of the zoo experience for zoo visitors as they relate to visitor attitudes, perceptions, and behaviors. Additionally, we shall discuss features of the zoo environment that have already been shown to affect zoo visitors' experiences and learning, and then pivot to the important discussion of where future research efforts may be best placed, to understand the bi-directional nature of AVIs in zoos.

\section{What is the Visitor Experience?}

The "visitor experience" when at a zoo, aquarium, or museum is something that has been variably defined, making direct comparisons of research into the visitor experience difficult. Here, we shall define the visitor experience as the overall, collective experience of visitors, which encompasses individual visitors' experiences and their perceptions, attitudes and behaviors towards the captive animals, 
enclosures, displays, signage, interactive programs, encounters, and conversations that they have while onsite. Visitors' interests when attending zoos, aquariums and museums have been studied regularly since the late-1990's, with visitors reporting reasons for attendance from purely for entertainment, or meeting at these venues for socializing (or bonding time) with other people; through to attending to fulfil a desire for "connection" with wild animals (though definitions of and types of "connections" that are sought are highly individualistic), to have a "close encounter" with wildlife, or for knowledge and education on animal and conservation-related issues (Balmford, 2000; Briseño-Garzón et al., 2007; Clayton et al., 2009; Davey, 2006a, b; D’Cruze et al., 2019; Falk et al., 2007, 2008; Fernandez et al., 2009; Godinez \& Fernandez, 2019; Howell et al., 2019; Roe \& McConney, 2015; Tribe \& Booth, 2003; Yalowitz, 2004). Usually, unless the visitors are part of a school or formal programmatic/educational visit, visitors are not attending these informal learning environments for the main purpose of self-education (Godinez \& Fernandez, 2019), but some learning in some visitors may still occur. "Visitor attraction models" describe visitor interests as the preferences and attraction of onsite visitors to certain animals, exhibits or presentations, and there are a range of methods employed to study these interests (Ballantyne et al., 2007; Godinez et al., 2013; Moss \& Esson, 2010; Whitworth, 2012).

With all these varied interests, measuring the effectiveness of conservation messaging, educational elements, and public presentations - that are designed to change visitor perceptions and attitudes while onsite and foster long-term changes in public conservation-caring after leaving - are somewhat marred by a quagmire of uncontrollable, interacting and/or confounding factors, and robust measurement techniques are currently lacking (Mellish et al., 2018). However, some clear contributing factors that influence visitor perceptions, attitudes, and behaviors have been identified, and more factors are being discovered with continued research in this area (Clayton et al., 2009; Fernandez et al., 2009; Godinez \& Fernandez, 2019). Some of these identified factors are: animal type/taxonomic group (Moss \& Esson, 2010; Whitworth, 2012), enclosure/exhibit design (Bitgood et al., 1988; Davey, 2006a, b; Nakamichi, 2007; Skibins \& Powell, 2013), animal visibility, activity and behaviors (Bitgood et al., 1988; Chiew, Hemsworth et al., 2019; Davey 2006a, b; Hacker \& Miller, 2016; Luebke et al., 2016; Margulis et al., 2003; Miller, 2013; Moss \& Esson, 2010; Philpot, 1996; Ridgway et al., 2005), perceived animal wellbeing and welfare (Bexell et al., 2007; Chiapero et al., 2021; Davey, 2007b; Escobar-Ibarra et al., 2021; Howell et al., 2019; Melfi et al., 2004; Miller, 2013; Miller et al., 2018; Packer et al., 2018; Razal \& Miller, 2019), proximity to the animal (Chiew, Hemsworth et al., 2019; Howell et al., 2019; Luebke et al., 2016; Whitehouse-Tedd et al., 2018), visual messaging/signage (Clayton et al., 2009; Read \& Waran, 1996), live animal training, educational programs and live-animal presentations (Alba et al., 2017; Anderson et al., 2003; Esson \& Moss, 2014; Fernandez et al., 2009; Kimble, 2014; Mann-Lang et al., 2016; Miller et al., 2013; Povey \& Rios, 2002; Sherwood et al., 1989; Spooner et al., 2019; Spooner, Jensen et al., 2021; Whitehouse-Tedd et al., 2018), and interactions or "close encounters" with animals, often including physical contact (D'Cruze et al., 2019; Hacker \& Miller, 2016; Hosey, 2005; Hotchkiss, 1991; Howell et al., 2019; Kreger \& Mench, 1995; Luebke et al., 2016; Luebke, 2018; Skibins \& Powell, 2013; Spooner, Farnworth et al., 2021; Whitehouse-Tedd et al., 2018; Whitehouse-Tedd et al., 2020). There are also many ethical (and welfare) issues with "close-contact" encounters with animals in zoos that must be explored/addressed if these experiences are to continue in modern, ethical zoos (Carr, 2018; D'Cruze et al., 2019; de Mori et al., 2019a, b; Learmonth, 2020; Rapp et al., 2017; Rose, 2018; Spooner, Farnworth et al., 2021; Whitehouse-Tedd et al., 2018). These ethical and welfare issues have been explored in-depth in Learmonth (2020), and most zoo and aquarium associations have established guidelines that must be adhered to by member institutions that offer these sorts of close-contact encounters (AZA, 2011; WAZA, 2020). Palmer and Sandøe (2016), and Palmer et al. (2018) have likewise explored ethical issues such as these, and questioned value-driven decisions about current and future collections of animals that zoos are housing.

Visitor interests have most often been studied through direct measures of their behavior - such as dwell time (sometimes referred to as "holding time") in front of or nearby enclosures/exhibits, attention towards an enclosure/exhibit (e.g., facing or talking about an exhibit), level of interaction with signage and/or interactive displays, and overall crowd size at presentations or an enclosure/exhibit (Anderson et 
al., 2003; Clayton et al., 2009; Fernandez et al., 2009; Godinez et al., 2013; Godinez \& Fernandez, 2019; Margulis et al., 2003; Read \& Waran, 1996) - or through visitor surveys conducted onsite at these destinations, with both formal (i.e., scientifically published) and informal (i.e., internally reported within the organization only) reporting outcomes (Chiapero et al., 2021; Chiew, Hemsworth et al., 2019; Dove \& Byrne, 2014; Clayton et al., 2017; Godinez \& Fernandez, 2019; Howell et al., 2019; Jensen, 2014a; Moss et al., 2015, 2017a; Penn, 2009; Spooner et al., 2019; Spooner, Jensen et al., 2021). However, as Spooner et al. (2019) and others note, "reporting on others' experience is prone to bias and must be viewed with caution" (p.1233) (Donaldson \& Grant-Vallone, 2002; Jensen, 2014b, 2017). This applies to both behavioral studies when the visitors are aware of being observed, and the results of visitor questionnaires, as visitors may be likely to try to predict favorable or desired responses and answer (or act) accordingly, rather than always answering honestly. Often these questionnaires also rely on retrospective items to collect information on visitors' pre-visit attitudes and behaviors (Mellish et al., 2018; Wyles et al., 2013), though some studies have deliberately collected initial questionnaires before visitors' entry to an attraction (Hoffmaster et al., 2016).

\section{Visitor Attitudes and Perceptions}

Often, visitor experience is influenced by preconceived beliefs and perceptions (based on past experiences) of the zoo that individual visitors have before attending, and these preconceived ideas influence their interests, attitudes, and behaviors when onsite. It is pertinent here to differentiate beliefs, attitudes, and perceptions as we define them. As in Chiew, Hemsworth et al. (2019), perceptions are defined as "an individual's interpretation of specific situations, stimuli or objects into something meaningful to them based on past experiences (Pickens, 2005)" (p. 2), and attitudes are defined as "the "mindset or tendency to act in a certain way where we are trying to understand or explain an individual's behavior (Pickens, 2005)" (p. 2). Attitudes are derived from internal beliefs (Ajzen, 1991), and are a strong determinant for that individual's behaviors (Ballantyne \& Packer, 2005). Observed relationships between human attitudes and behavior have now been well described by the Theory of Planned Behavior, which attempts to explain and predict a person's behavior (Ajzen, 1991). It proposes that the beliefs a person holds regarding a particular object form the attitudes of a person and their subjective norms, which in turn can predict and determine a person's intention and behavior (Ajzen, 1985, 1991). Therefore, knowledge and measurement of the attitudes and perceptions of visitors is important because they (particularly attitudes) are drivers of behavior (Ajzen 1991; Chiew et al., 2021). In psychology, it is well established that an individual's attitude is defined by three interconnected components: A person's beliefs about the object such as zoo animals (cognition), their emotional response to the object (affect) and their behavioral tendency towards the object (conation) (Ajzen, 1985; Albarracín et al., 2014; Hemsworth \& Coleman, 2011; Pickens, 2005). One or more of these three components can be used to infer an individual's underlying attitudes, when assessed in a questionnaire containing a series of attitude statements (Hemsworth \& Coleman, 2011; Pickens, 2005).

In the context of AVI's, there has been a recent proposed model of animal-visitor interactions that adapts the Hemsworth-Coleman model of stockperson-animal interactions (Hemsworth \& Coleman, 2011; Learmonth, 2019). Research on stockperson-animal interactions shows that the nature of the interactions between farm animals and stockpeople is influenced by a stockperson's attitude towards animals, their beliefs about other people's expectations of them as a stockperson, and their beliefs about the extent to which they have control over their ability to appropriately interact with the animals (Coleman et al., 2000; Hanna et al., 2009; Hemsworth et al., 1994). This results in the formation of a sequential relationship between the attitudes and behavior of humans and animal behavior and welfare (Hemsworth \& Coleman, 2011). By understanding this relationship, the negative effects of humans on animals such as fear and stress, can be minimized by targeting human attitudes to modify their behavior towards animals and thus, improve the management of human-animal interactions (Coleman et al., 2003; Ellingsen et al., 2014; Hemsworth, 2003; Hemsworth et al., 1994). Consequently, the model proposed in Learmonth (2019), the Chiew-Hemsworth model for zoo AVI's, highlights how the attitudes of visitors 
may be examined alongside the assessment of animal welfare to gain a more comprehensive understanding of the zoo visitor-animal relationship. However, examination of the attitudes and perceptions of visitors that may drive the way visitors behave towards zoo animals has been limited, with only a handful of studies thus far beginning to apply this model (Chiew, Hemsworth et al., 2019; Chiew et al., 2021).

Most research to date on visitor attitudes and perceptions has primarily focused on examining the effects of the various factors of the zoo environment and zoo experience on visitor attitudes and perceptions since it provides zoos with a better understanding of their visitors while at the zoo. As previously mentioned, there are several factors that influence visitor perceptions, attitudes, and behaviors (Clayton et al., 2009; Fernandez et al., 2009; Godinez \& Fernandez, 2019). One of the factors that has received a considerable amount of research has been the impact of zoo enclosure design on visitors (Bitgood et al., 1988; Finlay et al., 1988; Davey, 2006b; de Young et al., 2011; Moss et al., 2010; ShettelNeuber, 1988). For example, 'naturalistic' enclosures that promote the welfare of zoo animals are associated with increased positive visitor perceptions of and attitudes towards zoo animals, their welfare, and improved visitor experiences (Coe, 1985; Finlay et al., 1988; Luebke et al., 2016; Lukas \& Ross, 2014; Melfi et al., 2004; Nakamichi, 2007; Packer et al., 2018; Rhoads \& Goldsworthy, 1979; Tofield et al., 2003; Wolf \& Tymitz, 1981; Yilmaz et al., 2010, 2017). Free-range enclosures, which promote natural or species-specific behavior in zoo animals, have also been shown to improve visitor perceptions of the welfare of zoo animals, visitor experience and increase visitor viewing times (Bryan et al., 2017; Mun et al., 2013; Price et al., 1994; Wilson et al., 2003). Additionally, enclosures that have enrichment items for zoo animals have been found to increase visitor ratings of the enclosures, to be associated with positive perceptions of zoo animals and their welfare, to increase positive attitudes towards enrichment items, and to increase viewing times and interactions with zoo animals at exhibits by visitors (Davey et al., 2005; Davey, 2007a; Kutska, 2009; Roth et al., 2017; Tripp, 1985; Wood, 1998). For example, Roth et al. (2017) found that visitor attitudes towards carcass feeding were positive, which also increased positive attitudes towards animal welfare and behavior. However, there is variation within the literature on the effect of different types of enrichments (e.g., naturalistic vs. unnaturalistic) on visitor perceptions and attitudes where some have argued there can be substantial variation in visitor responses to enrichment, in particular to where it is provided (e.g., on exhibit or off exhibit; Cottle et al., 2010; Ings et al., 1997; McPhee et al., 1998), whereas others have found no effect of enrichment type on visitor perceptions (Kutska, 2009). It is worth noting, however, that it is also unclear as to whether these positive visitor perceptions of enclosures when enrichment is present is due to the visitors valuing 'enrichment' as an animal welfare strategy, or simply because enrichment may make the observed animals more visible or active.

There have also been a handful of studies that have shown the importance of visual messaging and signage, as well as physical or visual barriers, which can impact visitor perceptions, attitudes, behavior, and experience (Dancer \& Burn, 2019; Fogelberg, 2014; Kratochvil \& Schwammer, 1997; Reade \& Waran, 1996). For instance, Reade and Waran (1996) found visual messages that zoo visitors are exposed to within the zoo environment increased positive perceptions of zoo animals and increased awareness of the benefits of environmental enrichment. Signs at zoos directed at regulating visitor behaviors have been found to have varying effects depending on the wording, specificity and/or visual imagery included or not included (Chiew, Hemsworth et al., 2019; Dancer \& Burn, 2019; Parker et al., 2018). Chiew, Hemsworth et al. (2019) found that signs used to attempt to regulate potentially fearprovoking visitor behaviors towards little penguins (Eudyptula minor) had a negative effect on visitor attitudes towards some little penguin characteristics. No detrimental effect of signs was found on the overall attitudes of visitors towards little penguins, penguin welfare, the enclosure, or visitor experience. However, signs were found to be ineffective in regulating potentially fear-provoking visitor behaviors (Chiew, Butler et al., 2019; Chiew, Hemsworth et al., 2019). In contrast, Dancer and Burn (2019) found that signs requesting visitors to be quiet were effective in reducing visitor noise levels. Similarly, Parker et al. (2018) found that signs requesting visitors not to feed meerkats were effective in reducing the frequency of visitors feeding the meerkats, but increased attempts to touch the meerkats, which was 
suggested as a displacement behavior for not being able to feed the animals. However, these latter two studies did not examine visitor attitudes or perceptions; thus, it is unclear whether signs in these studies influenced visitor attitudes and perceptions. Interestingly, there is some evidence to suggest physical barriers that regulate the close proximity of visitors, or visual barriers that make animal exhibits more immersive and have positive effects on zoo animal welfare, can increase positive attitudes and perceptions of visitors towards zoo animals and these exhibits, can improve visitor experience, and can better regulate potentially negative visitor behaviors towards zoo animals (Blaney \& Wells, 2004; Chiew, Butler et al., 2019; Chiew, Hemsworth et al., 2019).

Another factor that has been sporadically researched is the effectiveness of specific conservation and education campaigns or programs on visitor perceptions and attitudes. These campaigns and programs have sometimes been found to increase positive visitor perceptions of, and attitudes towards, zoo animals, to promote conservation awareness, and increase pro-conservation behaviors (Ballantyne et al., 2011; Ballantyne et al., 2018; Clayton et al., 2009; Mellish et al., 2019; Pearson et al., 2014; Rabb \& Saunders, 2005; Skibins \& Powell, 2013; Tofield et al., 2003). This type of research is particularly important because it allows zoos to assess how effectively they are educating visitors about wildlife, and can incite behavioral changes in their visitors to help conservation efforts (Ballantyne et al., 2018; Godinez \& Fernandez, 2019; Howell et al., 2019; Skibins \& Powell, 2013; Smith et al., 2008).

\section{The Effects of Learning on Conservation Action}

Multiple studies, such as those above, have been undertaken (both internally in organizations, and externally reported in scientific literature) to evaluate the efficacy of visitation, conservation messaging and educational programs in both formal learning settings (e.g., scheduled school visits) and informal, free-choice learning (e.g., zoo visitors' engagement with signage or presentations; Bexell et al., 2007; Chalmin-Pui \& Perkins, 2017; Clayton, 2016; Collins et al., 2019; 2020a; 2020b; Dove \& Byrne, 2014; Escobar-Ibarra et al., 2021; Hayward \& Rothenberg, 2004; Lindemann-Matthies \& Kamer, 2005; Lukas \& Ross, 2005; Miller et al., 2013; Moss et al., 2014, 2015, 2017a, b; Nygren \& Ojalammi, 2018; Spooner et al., 2019; Spooner, Jensen et al., 2021). Indeed, even the American Association of Zoos and Aquariums (AZA) requires accredited facilities to consistently measure the effective impact of their conservation and educational programs/presentations to maintain accreditation (AZA, 2021), as do most of the other regional and global zoo and aquarium associations (Barongi et al., 2015; WAZA, 2005). Most of these studies have investigated direct conservation knowledge gains by comparing visitors' pre-visit knowledge (at point of arrival) with their knowledge of wildlife and conservation initiatives undertaken by individual institutions immediately after viewing certain exhibits, presentations, or engagements (such as Spooner et al., 2019). Zoo visitors have generally been found to have relatively extensive knowledge of anthropogenic impacts upon biodiversity conservation and environmental issues, even if they hold misconceptions regarding the concepts of biodiversity and ecosystems (Dove \& Byrne, 2014). However, very few of these studies have tried to quantify the long-term impacts of zoo visits (and specifically conservation-related presentations) on conservation knowledge retention (Collins et al., 2020b; Jensen, 2014b; Jensen et al., 2017; Moss et al., 2015, 2017b; Wagoner \& Jensen, 2010), and even fewer studies have tried to measure the conversion of this knowledge into effective pro-conservation actions (such as adopting pro-environmental behaviors or joining or donating to conservation causes) post-visit (Adelman et al., 2010; Collins et al., 2020b; Miller et al., 2013).

As has often been reported, increasing visitors' biodiversity and conservation knowledge does not necessarily result in the adoption of pro-environmental behaviors, but often it does increase the intention to adopt these sorts of behaviors (Clayton et al., 2017; Collins et al., 2020b; Hacker \& Miller, 2016; Howell et al., 2019; Moss et al., 2015, 2017a, b; Skibins \& Powell, 2013). Two of the largest barriers that visitors report for these low rates of behavioral change are that they are often uncertain how they should become involved other than donating money (Ojalammi \& Nygren, 2018), and that they lack the appropriate education, materials, or relevance to their daily lives to adopt the required behaviors outside of an immediate zoo visit context (Grajal et al., 2018; Smith et al., 2012; Stoinski et al., 2002; Swanagan, 
2000). Of the very few studies that have so far measured post-visit pro-conservation behaviors, when materials that were relevant to and easy to use in visitors' daily lives (such as Monterey Bay Aquarium's "Seafood Watch Pocket Guide" for helping to choose more sustainable seafood options) were included, there was a much higher rate of adoption of the intended behavior (51\% tried using the card) than for distribution of a card that simply detailed conservation organizations that could be investigated and joined voluntarily (10\% reported investigating organizations, but zero participants joined an organization; Yalowitz, 2004). Another pertinent barrier to the adoption of pro-conservation behaviors are demographically related factors, such as where individuals live and socio-economic status, rather than a lack of knowledge (Moss et al., 2017a). Thus, it has been urged by some researchers that zoos, aquariums, and museums not only need to better understand why visitors attend their attractions, but they must also be more concerned with (a) what visitors do after they leave, and (b) better inspire visitors' active engagement for animals, welfare, and conservation (Escobar-Ibarra et al., 2021; Safina, 2018). To achieve this, zoos may need to "widen the view of nature conservation, human-animal relations (HAR), and environmental education in zoos" (Nygren \& Ojalammi, 2018, as cited in Escobar-Ibarra et al., 2021, p. 2). Outside of the zoo education context, a recent study on the public perception of bats found that after attending a bat-focused festival including an educational exhibit on bats, most adult participants reported increased knowledge of, and intent to help, wild bats in both an immediate and a post-visit follow-up survey (Hoffmaster et al., 2016). Even more recently, Fukano et al. (2021) explored public perceptions and knowledge of the endangered Japanese rock ptarmigan (Lagopus muta japonica) after a mediareported 'debut' of captive-bred birds at five Japanese zoos, through direct online questionnaires and through other online sources of information (Google Trends, Wikipedia, Twitter, and donation website visits). They reported a significant increase in knowledge of the birds in prefectures where the birds naturally occur, and suggested that these 'debuts' have the potential to promote public awareness and knowledge of animals and conservation issues on a nationwide scale. This very novel research has attempted to measure indirect knowledge gains and awareness, using multiple measures of public media and internet engagement with conservation efforts by zoos. This is suggested as one of the key areas in which more research is necessary for us to fully understand the impacts of zoo-based education and conservation programs.

One significant predictor of increased knowledge of conservation issues, appreciation of wildlife, and the adoption of pro-conservation related behaviors is repeat visitation to zoos (Clayton et al., 2017; Godinez \& Fernandez, 2019; Lukas \& Ross, 2005; Miller et al., 2013; Moss et al., 2017a; Yalowitz, 2004). Though it has not yet been uncovered why some visitors are motivated to become repeat or frequent visitors over others. Two questions posed by Godinez and Fernandez (2019) to investigate this are: (a) do repeat visitors continue to visit zoos because they are already conservation-oriented and see zoological institutions as places to fulfil this area of interest? Or, (b) do they become more concerned with conservation issues over time as a result of the information and experiences they have in zoos? Perhaps repeat visitation gives these visitors more exposure and access to engage in in situ conservation actions (such as donating, signing petitions, or buying sustainable products from zoo shops) that may increase both their conservation literacy and their confidence in making pro-conservation choices in their daily lives. This supposition would fit with the reframed zoo visitor knowledge-action paradigm from Godinez and Fernandez (2019):

$$
\text { Visit with in situ action } \rightarrow \text { Knowledge } \rightarrow \text { Concern } \rightarrow \text { Intent } \rightarrow \text { Post-visit action }
$$

\section{Animals Affecting Visitors: What We Know So Far}

The theory that active animals attract visitors and increase observable visitor behaviors (the "visitor attraction model") is supported by several studies. Visitors spend more time, increase their conversations about animals, and congregate in larger groups when animals are present and active compared to when animals are inactive or out of sight (Altman, 1998; Anderson et al., 2003; Bitgood et al., 1988; Clayton et al., 2003; Collins et al., 2016; Davey, 2006a; Godinez et al., 2013; Sellinger \& Ha, 
2005). In addition to animal visibility is the actual size of an animal. Some studies suggest that visitors prefer larger-bodied animals (Bitgood et al., 1988; Ward et al., 1998). However, Balmford (2000) reanalyzed the results of Ward et al. (1998) and supplemented the data with additional data collected from London Zoo. They found no discernible difference between time visitors spent at exhibits of large-bodied animals compared to small-bodied animals. Specifically, Balmford cautioned that visitor preference toward certain animals may be negatively affected by external variables, such as time spent viewing an enclosure and crowd size. For example, smaller animals require less space and have smaller exhibits, thereby limiting the size of the visitor crowd capable of viewing that exhibit compared to bigger, largebodied animal exhibits. This lack of space, and extended dwell time of others, may dissuade some visitors from waiting for their turn at the front of those particular exhibits and they may divert their attention to more open, large exhibits instead.

The catalyst for increased visitor empathy and perceptions is also directly impacted by AVIs, particularly positive visitor experiences with animals in zoo environments (Clayton et al., 2009; Kutska, 2009). How visitors perceive their experience, and visitor opinions regarding the overall welfare of exhibited animals, can be greatly influenced by what behaviors they witness from the observed animals. Bexell et al. (2007) examined visitor perceptions of giant pandas while playing or not playing and found those who witnessed giant panda play were significantly more likely to rate their experience more positively than those who did not observe playing. Altman (1998) found visitor conversations changed based on bear behaviors, with animal behavior conversations occurring the most when the bears were active compared to pacing or out of sight. Furthermore, visitors reported the most positive emotions after witnessing active animals compared to when animals were out of sight or engaged in other behaviors (Luebke et al., 2016). Similarly, Chiew, Hemsworth et al. (2019) found that the closer, more visible, and active (e.g., increased swimming and diving) little penguins were to the visitor viewing area, the more positive visitor experience and visitor attitudes were towards little penguins, penguin welfare, the enclosure, learning, and exhibit manipulations. This particular study highlights how the fewer behaviors indicative of fear displayed by zoo animals such as avoidance, huddling and vigilance, and the more behaviors displayed by animals that are active, such as swimming and diving in penguins, can elicit more positive visitor attitudes toward the zoo animals, their welfare and the enclosure and improve visitor experience (Chiew, Hemsworth et al., 2019).

Another factor that influences visitor perceptions of animal behavior is how visitors interpret the behaviors being displayed. This is particularly important with regard to visitors observing stereotypic activity (repetitive, invariant behavior patterns with no obvious goal or function; Mason, 1991; Mason \& Latham, 2004). In a study by Godinez et al. (2013), the researchers examined how visitors identified the predominant behaviors displayed by a jaguar in correlation with visitor activity and their ratings of the animal's wellbeing, exhibit quality, and the visitor's enjoyment. Overall, visitors were able to accurately describe a jaguar's behavior as inactive, active, or out of sight. However, approximately half of all visitors described stereotypic pacing as non-repetitive, active behavior. For visitors who described a pacing pattern or other repetitive behaviors correctly as stereotypic, they were also significantly more likely to rate the jaguar's well-being, exhibit quality, and visitor enjoyment lower than those who described the behavior as non-repetitive, active behavior. Similarly, Miller (2013) found that participants rated the overall welfare of a tiger lower and were less likely to support zoos after witnessing tiger pacing compared to those who observed an inactive tiger.

While zoos have made significant strides in reducing stereotypic activity displayed by their animals through enrichment and other efforts, these studies suggest that visitors view stereotypies as an indicator of poor welfare, which affects multiple aspects of their own behavior and perceptions towards zoos and zoo animals. Future studies could examine education interventions with visitors highlighting behavioral enrichment and other welfare-oriented procedures, and if these efforts affect visitor views of exhibited animals and a zoo's ability to care for them. 


\section{Zoo Visitors vs. Non-Visitors}

The last area of inquiry that has still not been thoroughly investigated is whether significant differences exist between zoo visitors and non-visitors (i.e., those who have not recently visited a zoo) in terms of conservation literacy, connection with animals, and the adoption of important pro-environmental and pro-conservation behaviors. Almost all the research above has focused exclusively on zoo visitors as they entered the attraction (Fernandez, 2019; Godinez \& Fernandez, 2019), and the only study that did attempt a visitor - non-visitor comparison (Read \& Waran, 1996) recruited non-visitors from immediately in front of a zoo attraction (defined as those who were present but did not enter the attraction), and this group's conservation knowledge and attitudes were not measured. This is the first area we suggest needs to be addressed by the scientific community, not only in human-related fields like psychology, but also in predominantly animal-related fields such as animal welfare, as the attitudes and perceptions of society are relevant to the operation and continuation of many captive animal industries.

\section{Conclusions: Future Visitor Experience Research}

As suggested above, future research needs to address why visitors are attending zoos, aquariums, and museums, and especially why repeat visitors continue to return. This future research also needs to make a concerted effort to understand: (a) what visitors are doing after they leave the zoo, and (b) whether visitors are adopting long-term pro-conservation behaviors. Thus, much more research effort, more collaboration between zoos and educational institutions, and more funding should be assigned to longitudinal studies of visitor attitudes and behaviors, ideally in comparative studies with non-visitor groups as well (Fernandez, 2019; Fernandez \& Timberlake, 2008; Godinez \& Fernandez, 2019). We must also focus more acutely on the effects that captive animals are having upon the perceptions and attitudes of visitors after AVIs, and whether these effects are more profound for visitors after close-contact experiences, or simply related to the visitors' perceived 'connection' to the animal(s) with or without a close-contact experience (D’Cruze et al., 2019; Godinez \& Fernandez, 2019; Howell et al., 2019; Learmonth, 2020). Additionally, there is a need for further focus on understanding the attitudes of visitors that may drive the way visitors behave towards zoo animals to help better manage the interactions between visitors and zoo animals (Chiew, Hemsworth et al., 2019; Chiew et al., 2021).

In addition, it is suggested here that visitor interests, attitudes, and perceptions must be better understood if we plan to investigate indirect measures related to the visitor experience as well. That is, measuring variables such as: individual conservation support outside of the zoo (donations or involvement with conservation or advocacy organizations), internet activity (how much traffic is coming through specific parts of zoos' websites? Is there a measurable increase in website traffic if visitors are directed to specific web pages during their visit?), changes in sustainable purchasing practices related to knowledge gains, financial investment in sustainable or ethical companies after knowledge gains, and longitudinal effects of zoo visits (how long do pro-conservation behaviors persist?).

Finally, there is an immediate need to move to measuring practical gains to conservation-related purposes that zoos are championing. Currently, much theoretical work has paved the way for understanding visitor interests, engagement with information, and retention of knowledge. But practical contributions of visitors to conservation (from both direct and indirect measures of their actions) are still lacking clarity. Quantifying exactly how zoo animals affect zoo visitors during visits would be a pertinent first step in progressing practical measures of the overall effects of zoo visitation. To better understand how visitors 'connect' with animals, and whether this caring increases practical support, would be greatly beneficial to both scientific understanding as well as to zoo operations. Furthermore, investigating how visitors assess their own experience while at the zoo, and asking them to critically assess their behaviors and attitudes while at the zoo would be interesting for completing the holistic picture of what a zoo visit means to zoo visitors, and how zoos can improve the 'visitor experience' while maintaining and protecting modern standards of animal welfare. 
Funding and Conflict of Interest: This work received no funding, and we have no known conflicts of interest to disclose.

\section{References}

Adelman, L. M., Falk, J. F., \& James, S. (2010). Impact of national aquarium in Baltimore on visitors' conservation attitudes, behavior, and knowledge. Curator: The Museum Journal, 43(1), 33-41. https://doi.org/10.1111/j.2151-6952.2000.tb01158.x

Ajzen, I. (1985). From intentions to actions: A theory of planned behavior. In J. Kuhl \& J. Beckmann (Eds.) Actioncontrol: From cognition to behavior (pp. 11-39). Springer. https://doi.org/10.1007/978-3-642-69746-3_2

Ajzen, I. (1991). The theory of planned behavior. Organizational Behavior and Human Decision Processes, 50(2), 179-211. https://doi.org/10.1016/0749-5978(91)90020-T

Alba, A. C., Leighty, K. A., Pittman Courte, V. L., Grand, A. P., \& Bettinger, T. L. (2017). A turtle cognition research demonstration enhances visitor engagement and keeper-animal relationships. Zoo Biology, 36(4), 243-49. https://doi.org/10.1002/zoo.21373

Albarracín, D., Johnson, B. T., \& Zanna, M. P. (2014). The handbook of attitudes, 2nd ed. Psychology Press. https://doi.org/10.4324/9781410612823

Altman, J. D. (1998). Animal activity and visitor learning at the zoo. Anthrozoös, 11(1), 12-21. https://doi.org/10.1080/08927936.1998.11425083

Anderson, U. S., Kelling, A. S., Pressley-Keough, R., Bloomsmith, M. A., \& Maple, T. L. (2003). Enhancing the zoo visitor's experience by public animal training and oral interpretation at an otter exhibit. Environment and Behavior, 35(6), 826-841. https://doi.org/10.1177/0013916503254746

Association of Zoos and Aquariums (AZA). (2011). Animal ambassador policy. https://www.aza.org/azaambassador-animal-policy

Association of Zoos and Aquariums (AZA). (2021). AZA accreditation standards. https://www.aza.org/assets/2332/aza-accreditation-standards.pdf

Ballantyne, R., Hughes, K., Lee, J., Packer, J., \& Sneddon, J. (2018). Visitors' values and environmental learning outcomes at wildlife attractions: Implications for interpretive practice. Tourism Management, 64, 190-201. https://doi.org/10.1016/j.tourman.2017.07.015

Ballantyne, R., \& Packer, J. (2005). Promoting environmentally sustainable attitudes and behaviour through free-choice learning experiences: What is the state of the game? Environmental Education Research, 11(3), 281-295, https://doi.org/10.1080/13504620500081145

Ballantyne, R., Packer, J., \& Falk, J. (2011). Visitors' learning for environmental sustainability: Testing short- and long-term impacts of wildlife tourism experiences using structural equation modelling. Tourism Management, 32(6), 1243-1252. https://doi.org/10.1016/j.tourman.2010.11.003

Ballantyne, R., Packer, J., Hughes, K., \& Dierking, L. (2007). Conservation learning in wildlife tourism settings: Lessons from research in zoos and aquariums. Environmental Education Research, 13(3), 367-383. https://doi.org/10.1080/13504620701430604

Balmford, A. (2000). Separating fact from artifact in analyses of zoo visitor preferences. Conservation Biology, 14(4), 1193-1195. https://doi.org/10.1046/j.1523-1739.2000.99078.x

Barongi, R., Fisken, F. A., Parker, M., \& Gusset, M. (2015). Committing to conservation: The World Zoo and aquarium conservation strategy. https://www.waza.org/wp-content/uploads/2019/03/WAZA-ConservationStrategy-2015 Portrait.pdf

Bexell, S., Jarrett, O. S., Lan, L., Yan, H., Sandhaus, E. A., Zhihe, Z., \& Maple, T. L. (2007). Observing panda play: Implications for zoo programming and conservation efforts. Curator: The Museum Journal, 50(3), 287297. https://doi.org/10.1111/j.2151-6952.2007.tb00273.x

Binding, S., Farmer, H., Krusin, L., \& Cronin, K. (2020). Status of animal welfare research in zoos and aquariums: Where are we, where to next? Journal of Zoo and Aquarium Research, 8(3), 166-174. https://doi.org/10.19227/jzar.v8i3.505

Bitgood, S., Patterson, D., \& Benefield, A. (1988). Exhibit design and visitor behavior: Empirical relationships. Environment and Behavior, 20(4), 474-491. https://doi.org/10.1177/0013916588204006

Blaney, E., \& Wells, D. (2004). The influence of a camouflage net barrier on the behaviour, welfare and public perceptions of zoo-housed gorillas. Animal Welfare, 13(2), 111-118. 
Briseño-Garzón, A., Anderson, D., \& Anderson, A. (2007). Entry and emergent agendas of adults visiting an aquarium in family groups. Visitor Studies, 10(1), 73-89. https://doi.org/10.1080/10645570701263461

Bryan, K., Bremner-Harrison, S., Price, E., \& Wormell, D. (2017). The impact of exhibit type on behaviour of caged and free-ranging tamarins. Applied Animal Behaviour Science, 193, 77-86. https://doi.org/10.1016/j.applanim.2017.03.013

Carder, G., \& Semple, S. (2008). Visitor effects on anxiety in two captive groups of western lowland gorillas. Applied Animal Behaviour Science, 115(3-4), 211-220. https://doi.org/10.1016/j.applanim.2008.06.001

Carr, N. (2018). Zoos and animal encounters: To touch or not to touch. In N. Carr \& J. Young (Eds.), Wild animals and leisure: Rights and wellbeing (pp. 80-95). Routledge.

Carr, N., \& Cohen, S. (2011). The public face of zoos: Images of entertainment, education and conservation. Anthrozoös, 24(2), 175-189. https://doi.org/10.2752/175303711X12998632257620

Chalmin-Pui, L. S., \& Perkins, R. (2017). How do visitors relate to biodiversity conservation? An analysis of London Zoo's 'BUGS' exhibit. Environmental Education Research, 23(10), 1462-1475. https://doi.org/10.1080/13504622.2016.1259395

Chiapero, F., Ferrari, R. H., Guglielmetti, A., García Capocasa, M. C., \& Busso, J. M. (2021). Visitors' perceptions of zoo-housed lesser anteater (Tamandua tetradactyla) welfare: Observation plays a larger role than a brief informative talk. Zoo Biology, 40(1), 33-43. https://doi.org/10.1002/zoo.21574

Chiew, S. J., Butler, K. L., Sherwen, S. L., Coleman, G. J., Fanson, K. V., \& Hemsworth, P. H. (2019). Effects of regulating visitor viewing proximity and the intensity of visitor behaviour on little penguin (Eudyptula minor) behaviour and welfare. Animals, 9(6), 285-304. https://doi.org/10.3390/ani9060285

Chiew, S. J., Butler, K. L., Sherwen, S. L., Coleman, G. J., Melfi, V., Burns, A., \& Hemsworth, P. H. (2020). Effect of covering a visitor viewing area window on the behaviour of zoo-housed little penguins (Eudyptula minor). Animals, 10(7), 1224. https://doi.org/10.3390/ani10071224

Chiew, S. J., Hemsworth, P. H., Melfi, V., Sherwen, S. L., Burns, A., \& Coleman, G. J. (2021). Visitor attitudes toward little penguins (Eudyptula minor) at two Australian zoos. Frontiers in Psychology, 12(284), 1-13. https://doi.org/10.3389/fpsyg.2021.626185

Chiew, S. J., Hemsworth, P. H., Sherwen, S. L., Melfi, V., \& Coleman, G. J. (2019). The effect of regulating zoo visitor - penguin interactions on zoo visitor attitudes. Frontiers in Psychology, 10(2351), 1-14. https://doi.org/10.3389/fpsyg.2019.02351

Claxton, A. M. (2011). The potential of the human-animal relationship as an environmental enrichment for the welfare of zoo-housed animals. Applied Animal Behaviour Science, 133(1-2), 1-10. https://doi.org/10.1016/j.applanim.2011.03.002

Clayton, S., Fraser, J., \& Saunders, C. (2009). Zoo experiences: Conversations, connections, and concern for animals. Zoo Biology, 28(5), 377-397. https://doi.org/10.1002/zoo.20186

Clayton, S., Prevot, A. C., Germain, L., \& Saint-Jalme, M. (2017). Public support for biodiversity after a zoo visit: Environmental concern, conservation knowledge, and self-efficacy. Curator: The Museum Journal, 60(1), 87-100. https://doi.org/10.1111/cura. 12188

Coe, J. C. (1985). Design and perception: Making the zoo experience real. Zoo Biology, 4(2), 197-208. https://doi.org/10.1002/zoo.1430040211

Coleman, G. J., Hemsworth, P. H., Hay, M., \& Cox, M. (2000). Modifying stockperson attitudes and behaviour towards pigs at a large commercial farm. Applied Animal Behaviour Science, 66(1), 11-20. https://doi.org/10.1016/S0168-1591(99)00073-8

Coleman, G. J., McGregor, M., Hemsworth, P. H., Boyce, J., \& Dowling, S. (2003). The relationship between beliefs, attitudes and observed behaviours of abattoir personnel in the pig industry. Applied Animal Behaviour Science, 82(3), 189-200. https://doi.org/10.1016/S0168-1591(03)00057-1

Collins, C., Corkery, I., McKeown, S., McSweeney, L., Flannery, K., Kennedy, D., \& O’Riordan, R. (2020a). An educational intervention maximizes children's learning during a zoo or aquarium visit. The Journal of Environmental Education, 51(5), 361-380. https://doi.org/10.1080/00958964.2020.1719022

Collins, C., Corkery, I., McKeown, S., McSweeney, L., Flannery, K., Kennedy, D., \& O’Riordan, R. (2020b). Quantifying the long-term impact of zoological education: A study of learning in a zoo and an aquarium. Environmental Education Research, 26(7), 1008-1026. https://doi.org/10.1080/13504622.2020.1771287

Collins, C., Quirke, T., McKeown, S., Flannery, K., Kennedy, D., \& O'Riordan, R. (2019). Zoological education: Can it change behaviour? Applied Animal Behaviour Science, 220, 104857. https://doi.org/10.1016/j.applanim.2019.104857 
Collins, C., Quirke, T., Overy, L., Flannery, K., \& O'Riordan, R. (2016). The effect of the zoo setting on the behavioural diversity of captive gentoo penguins and the implications for their educational potential. Journal of Zoo and Aquarium Research, 4(2), 85-90. https://doi.org/10.19227/jzar.v4i2.158

Cottle, L., Tamir, D., Hyseni, M., Bühler, D., \& Lindemann-Matthies, P. (2010). Feeding live prey to zoo animals: Response of zoo visitors in Switzerland. Zoo Biology, 29(3), 344-350. https://doi.org/10.1002/zoo.20261

Dancer, A. M. M., \& Burn, C. C. (2019). Visitor effects on zoo-housed Sulawesi crested macaque (Macaca nigra) behaviour: Can signs with 'watching eyes' requesting quietness help? Applied Animal Behaviour Science, 211, 88-94. https://doi.org/10.1016/j.applanim.2018.12.005

Davey, G. (2006a). Relationships between exhibit naturalism, animal visibility and visitor interest in a Chinese zoo. Applied Animal Behaviour Science, 96(1-2), 93-102. https://doi.org/10.1016/j.applanim.2005.04.018

Davey, G. (2006b). Visitor behavior in zoos: A review. Anthrozoös, 19(2), 143-157. https://doi.org/10.2752/089279306785593838

Davey, G. (2007a). Visitors' effects on the welfare of animals in the zoo: A review. Journal of Applied Animal Welfare Science, 10(2), 169-183. https://doi.org/10.1080/10888700701313595

Davey, G. (2007b). Public perceptions in urban China toward zoos and their animal welfare. Human Dimensions of Wildlife, 12(5), 367-374. https://doi.org/10.1080/10871200701555188

Davey, G., Henzi, P., \& Higgins, L. (2005). The influence of environmental enrichment on Chinese visitor behavior. Journal of Applied Animal Welfare Science, 8(2), 131-140. https://doi.org/10.1207/s15327604jaws0802 5

D'Cruze, N., Khan, S., Carder, G., Megson, D., Coulthard, E., Norrey, J., \& Groves, G. (2019). A global review of animal-visitor interactions in modern zoos and aquariums and their implications for wild animal welfare. Animals, 9(6), 332. https://doi.org/10.3390/ani9060332

de Young, R., Dotzour, A., Houston, C., Manubay, G., Saunders, C. D., Schulz, K., \& Smith, J. (2011). Some immediate and longer-term effects of a zoo exhibit. Journal of Environmental Systems, 33(1), 19-28. https://doi.org/10.2190/ES.33.1.b

Donaldson, S. I., \& Grant-Vallone, E. J. (2002). Understanding self-report bias in organizational behavior research. Journal of Business and Psychology, 17(2), 245-60. https://doi.org/10.1023/A:1019637632584

Dove, T., \& Byrne, J. (2014). Do zoo visitors need zoology knowledge to understand conservation messages? An exploration of the public understanding of animal biology and of the conservation of biodiversity in a zoo setting. International Journal of Science Education, 4(4), 323-42. https://doi.org/10.1080/21548455.2013.822120

Ellingsen, K., Coleman, G. J., Lund, V., \& Mejdell, C. M. (2014). Using qualitative behaviour assessment to explore the link between stockperson behaviour and dairy calf behaviour. Applied Animal Behaviour Science, 153, 10-17. https://doi.org/10.1016/j.applanim.2014.01.011

Escobar-Ibarra, I., Mota-Rojas, D., Gual-Sill, F., Sánchez, C. R., Baschetto, F., \& Alonso-Spilsbury, M. (2021). Conservation, animal behaviour, and human-animal relationship in zoos. Why is animal welfare so important? Journal of Animal Behaviour and Biometeorology, 9(2), 2111. https://doi.org/10.31893/jabb.21011

Esson, M., \& Moss, A. (2014). Zoos as a context for reinforcing environmentally responsible behaviour: The dual challenges that zoo educators have set themselves. Journal of Zoo and Aquarium Research, 2(1), 8-13. https://doi.org/10.19227/jzar.v2i1.25

Falk, J. H., Reinhard, E. M., Vernon, C. L., Bronnenkant, K., Deans, N. L., \& Heimlich, J. E. (2007). Why zoos and aquariums matter: Assessing the impact of a visit to a zoo or aquarium. American Association of Zoos \& Aquariums.

Falk, J. H., Heimlich, J. E., \& Bronnenkant, K. (2008). Using identity-related visit motivations as a tool for understanding adult zoo and aquarium visitors meaning making. Curator: The Museum Journal, 51(1), 5579. https://doi.org/10.1111/j.2151-6952.2008.tb00294.x

Fanson, K., \& Wielebnowski, N. (2013). Effect of housing and husbandry practices on adrenocortical activity in captive Canada lynx (Lynx canadensis). Animal Welfare, 22(2), 159-165. https://doi.org/10.7120/09627286.22.2.159

Fernandez, E. J. (2019). What are we doing to measure conservation support from zoo visitors? AZA Conservation Education Committee Newsletter 13(2), 14-15.

Fernandez, E., Tamborski, M., Pickens, S., \& Timberlake, W. (2009). Animal-visitor interactions in the modern zoo: Conflicts and interventions. Applied Animal Behaviour Science, 120(1-2), 1-8. https://doi.org/10.1016/j.applanim.2009.06.002

Fernandez, E. J., \& Timberlake, W. (2008). Mutual benefits of research collaborations between zoos and academic institutions. Zoo Biology, 27(6), 470-487. https://doi.org/10.1002/zoo.20215 
Fernandez, E. J., Upchurch, B., \& Hawkes, N. C. (2021). The effects of public feeding on the activity of zoo-housed elephants. Animals, 11(6), 1689. https://doi.org/10.3390/ani11061689

Finlay, T. W., James, L. R., \& Maple, T. L. (1988). People's perceptions of animals: The influence of zoo environment. Environment and Behavior, 20(4), 508-528. https://doi.org/10.1177/0013916588204008

Fogelberg, K. (2014). Unsilencing voices: A study of zoo signs and their language of authority. Cultural Studies of Science Education, 9(4), 787-799. https://doi.org/10.1007/s11422-013-9566-8

Fukano, Y., Soga, M., Fukuda, M., Takahashi, Y., Koyama, M., Arakawa, Y., Miyano, N., Akiba, Y., \& Horiguchi, M. (2021). Debut of an endangered bird in zoos raises public interest, awareness and conservation knowledge of the species. Animal Conservation. Advance online publication https://doi.org/10.1111/acv.12693

Godinez, A. M., \& Fernandez, E. J. (2019). What is the zoo experience? How zoos impact a visitor's behaviors, perceptions, and conservation efforts. Frontiers in Psychology, 10, 1746. https://doi.org/10.3389/fpsyg.2019.01746

Godinez, A., Fernandez, E. J., \& Morrissey, K. (2013). Visitor behaviors and perceptions of jaguar activities. Anthrozoös, 26(4), 613-619. https://doi.org/10.2752/175303713X13795775535850

Gusset, M., \& Dick, G. (2011). The global reach of zoos and aquariums in visitor numbers and conservation expenditures. Zoo Biology, 30(5), 566-569. https://doi.org/10.1002/zoo.20369

Grajal, A., Luebke, J. F., \& Kelly, L. D. (2018). Why zoos have animals: Exploring the complex pathway from experiencing animals to pro-environmental behaviors. In B. A. Minteer, J. Maienschein, \& J. P. Collins (Eds.), The ark and beyond: The evolution of zoo and aquarium conservation (pp. 192-203). University of Chicago Press. https://doi.org/10.7208/chicago/9780226538631.003.0016

Gray, J. (2017). Zoo ethics: The challenges of compassionate conservation. CSIRO Publishing. https://doi.org/10.1071/9781486306992

Hacker, C. E., \& Miller, L. J. (2016). Zoo visitor perceptions, attitudes, and conservation intent after viewing African elephants at the San Diego Zoo Safari Park. Zoo Biology, 35(4), 355-361. https://doi.org/10.1002/zoo.21303

Hanna, D., Sneddon, I. A., \& Beattie, V. E. (2009). The relationship between the stockperson's personality and attitudes and the productivity of dairy cows. Animal, 3(5), 737-743. https://doi.org/10.1017/s1751731109003991

Hayward, J., \& Rothenberg, M. (2004). Measuring success in the "Congo Gorilla Forest" conservation exhibition. Curator: The Museum Journal, 47(3), 261-282. https://doi.org/10.1111/j.2151-6952.2004.tb00125.x

Hemsworth, P. H. (2003). Human-animal interactions in livestock production. Applied Animal Behaviour Science, 81(3), 185-198. https://doi.org/10.1016/S0168-1591(02)00280-0

Hemsworth, P. H., \& Coleman, G. J. (2011). Human-livestock interactions: The stockperson and the productivity and welfare of intensively farmed animals, 2 nd ed. $\mathrm{CAB}$ International. https://doi.org/10.1079/9781845936730.0000

Hemsworth, P. H., Coleman, G. J., \& Barnett, J. L. (1994). Improving the attitude and behaviour of stockpersons towards pigs and the consequences on the behaviour and reproductive performance of commercial pigs. Applied Animal Behaviour Science, 39(3-4), 349-362. https://doi.org/10.1016/0168-1591(94)90168-6

Hoffmaster, E., Vonk, J., \& Mies, R. (2016). Education to action: Improving public perception of bats. Animals, 6(1), 6. https://doi.org/10.3390/ani6010006

Hosey, G. R. (2005). How does the zoo environment affect the behaviour of captive primates? Applied Animal Behaviour Science, 90(2), 107-129. https://doi.org/10.1016/j.applanim.2004.08.015

Hotchkiss, N. A. (1991). The pros and cons of live animal contact. Journal of Museum Education, 16(2), 14-16. https://doi.org/10.1080/10598650.1991.11510172

Howell, T. J., McLeod, E. M., \& Coleman, G. J. (2019). When zoo visitors "connect" with a zoo animal, what does that mean? Zoo Biology, 38(6), 461-470. https://doi.org/10.1002/zoo.21509

Ings, R., Waran, N. K., \& Young, R. J. (1997). Attitude of zoo visitors to the idea of feeding live prey to zoo animals. Zoo Biology, 16(4), 343-347. https://doi.org/10.1002/(SICI)1098-2361(1997)16:4\%3C343::AIDZOO6\%3E3.0.CO;2-A

Jensen, E. A. (2014a). Evaluating children's conservation biology learning at the zoo. Conservation Biology, 28(4), 1004-1011. https://doi/org/10.1111/cobi.12263

Jensen, E. A. (2014b). The problems with science communication evaluation. JCOM Journal of Science Communication, 01(2014), C04. https://doi.org/10.22323/2.13010304

Jensen, E. A., Moss, A., \& Gusset, M. (2017). Quantifying long-term impact of zoo and aquarium visits on biodiversity-related learning outcomes. Zoo Biology, 36(4), 294-297. https://doi.org/10.1002/zoo.21372 
Jones, H., McGregor, P. K., Farmer, H. L., \& Baker, K. R. (2016). The influence of visitor interaction on the behavior of captive crowned lemurs (Eulemur coronatus) and implications for welfare. Zoo Biology, 35(3), 222-227. https://doi.org/10.1002/zoo.21291

Keay, J. M., Singh, J., Gaunt, M. C., \& Kaur, T. (2006). Fecal glucocorticoids and their metabolites as indicators of stress in various mammalian species: A literature review. Journal of Zoo and Wildlife Medicine, 37(3), 234-244. https://doi.org/10.1638/05-050.1

Kimble, G. (2014). Children learning about biodiversity at an environment centre, a museum and at live animal shows. Studies in Educational Evaluation, 41, 48-57. https://doi.org/10.1016/j.stueduc.2013.09.005

Kratochvil, H., \& Schwammer, H. (1997). Reducing acoustic disturbances by aquarium visitors. Zoo Biology, 16(4), 349-353. https://doi.org/10.1002/(SICI)1098-2361(1997)16:4\%3C349::AID-ZOO7\%3E3.0.CO;2-A

Kreger, M. D., \& Mench, J. A. (1995). Visitor-animal interactions at the zoo. Anthrozoös, 8(3), $143-158$. https://doi.org/10.2752/089279395787156301

Kuhar, C. W. (2008). Group differences in captive gorillas' reaction to large crowds. Applied Animal Behaviour Science, 110(3-4), 377-385. https://doi.org/10.1016/j.applanim.2007.04.011

Kutska, D. (2009). Variation in visitor perceptions of a polar bear enclosure based on the presence of natural vs. unnatural enrichment items. Zoo Biology, 28(4), 292-306. https://doi.org/10.1002/zoo.20226

Larsen, M. J., Sherwen, S. L., \& Rault, J.-L. (2014). Number of nearby visitors and noise level affect vigilance in captive koalas. Applied Animal Behaviour Science, $154, \quad 76-82$. https://doi.org/10.1016/j.applanim.2014.02.005

Learmonth, M. J. (2019). Dilemmas for natural living concepts of zoo animal welfare. Animals, 9(6), 318. https://doi.org/10.3390/ani9060318

Learmonth, M. J. (2020). Human-animal interactions in zoos: What can compassionate conservation, conservation welfare and duty of care tell us about the ethics of interacting, and avoiding unintended consequences? Animals, 10(11), 2037. https://doi.org/10.3390/ani10112037

Learmonth, M. J., Sherwen, S., \& Hemsworth, P. H. (2018). Effects of zoo visitors on quokka (Setonix brachyurus) avoidance behavior in a walk-through exhibit. Zoo Biology, 37(1), $223-228$. https://doi.org/10.1002/zoo.21433

Lindemann-Matthies, P., \& Kamer, T. (2005). The influence of an interactive educational approach on visitors' learning in a Swiss zoo. Science Education, 90(2), 296-315. https://doi.org/10.1002/sce.20127

Luebke, J. F., Watters, J. V., Packer, J., Miller, L. J., \& Powell, D. M. (2016). Zoo visitors' affective responses to observing animal behaviors. Visitor Studies, 19(1), 60-76. https://doi.org/10.1080/10645578.2016.1144028

Lukas, K. E., \& Ross, S. R. (2014). Naturalistic exhibits may be more effective than traditional exhibits at improving zoo-visitor attitudes toward African apes. Anthrozoös, 27(3), 435-455. https://doi.org/10.2752/175303714X14023922797904

Mann-Lang, J. B., Ballantyne, R., \& Packer, J. (2016). Does education mean less fun? A comparison of two animal presentations. International Zoo Yearbook, 50(1), 155-164. https://doi.org/10.1111/izy.12114

Margulis, S. W., Hoyos, C., \& Anderson, M. (2003). Effect of felid activity on zoo visitor interest. Zoo Biology, 22(6), 587-599. https://doi.org/10.1002/zoo.10115

Mason, G. J. (1991). Stereotypies: A critical review. Animal Behaviour, 41(6), 1015-1037. https://doi.org/10.1016/S0003-3472(05)80640-2

Mason, G. J., \& Latham, N. R. (2004). Can't stop, won't stop: Is stereotypy a reliable animal welfare indicator? Animal Welfare, 13(Suppl), S57-S69.

McPhee, M. E., Foster, J. S., Sevenich, M., \& Saunders, C. D. (1998). Public perceptions of behavioral enrichment: Assumptions gone awry. Zoo Biology, 17(6), 525-534. http://dx.doi.org/10.1002/(SICI)10982361(1998)17:6\%3C525::AID-ZOO6\%3E3.0.CO;2-W

Melfi, V.A., McCormick, W., \& Gibbs, A. (2004). A preliminary assessment of how zoo visitors evaluate animal welfare according to enclosure style and the expression of behavior. Anthrozoös, 17(2), 98-108. https://doi.org/10.2752/089279304786991792

Mellish, S., Pearson, E. L., McLeod, E. M., Tuckey, M. R., \& Ryan, J. C. (2019). What goes up must come down: An evaluation of a zoo conservation-education program for balloon litter on visitor understanding, attitudes, and behaviour. Journal of Sustainable Tourism, 27(9), 1393-1415. https://doi.org/10.1080/09669582.2019.1625908

Mellish, S., Ryan, J. C., Pearson, E. L., \& Tuckey, M. R. (2018). Research methods and reporting practices in zoo and aquarium conservation-education evaluation. Conservation Biology, 33(1), 40-52. https://doi.org/10.1111/cobi.13177 
Miller, L. J. (2013). Visitor reaction to pacing behavior: Influence on the perception of animal care and interest in supporting zoological institutions. Zoo Biology, 31(2), 242-248. https://doi.org/10.1002/zoo.20411

Miller, L. J., Luebke, J. F., \& Matiasek, J. (2018). Viewing African and Asian elephants at accredited zoological institutions: Conservation intent and perceptions of animal welfare. Zoo Biology, 37(6), 466-477. https://doi.org/10.1002/zoo.21445

Miller, L. J., Zeigler-Hill, V., Mellen, J., Koeppel, J., Greer, T., \& Kuczaj, S. (2013). Dolphin shows and interaction programs: Benefits for conservation education? Zoo Biology, 32(1), 45-53. https://doi.org/10.1002/zoo.21016

Mitchell, G., Tromborg, C. T., Kaufman, J., Bargabus, S., Simoni, R., \& Geissler, V. (1992). More on the 'influence' of zoo visitors on the behavior of captive primates. Applied Animal Behaviour Science, 35(2), 189-198. https://doi.org/10.1016/0168-1591(92)90009-Z

Moss, A., \& Esson, M. (2010). Visitor interest in zoo animals and the implications for collection planning and zoo education programmes. Zoo Biology, 29(6), 715-731. https://doi.org/10.1002/zoo.20316

Moss, A., Esson, M., \& Francis, D. (2010). Evaluation of a third-generation zoo exhibit in relation to visitor behavior and interpretation use. Journal of Interpretation Research, 15(2), 11-28. http://doi.org/10.1177/109258721001500203

Moss, A., Jensen, E., \& Gusset, M. (2014). Zoo visits boost biodiversity literacy. Nature, 508, 186. https://doi.org/10.1038/508186d

Moss, A., Jensen, E., \& Gusset, M. (2015). Evaluating the contribution of zoos and aquariums to Aichi Biodiversity Target 1. Conservation Biology, 29(2), 537-544. https://doi.org/10.1111/cobi.12383

Moss, A., Jensen, E., \& Gusset, M. (2017a). Probing the link between biodiversity-related knowledge and selfreported proconservation behavior in a global survey of zoo visitors. Conservation Letters, 10(1), 33-40. https://doi.org/10.1111/conl.12233

Moss, A., Jensen, E., \& Gusset, M. (2017b). Impact of a global biodiversity education campaign on zoo and aquarium visitors. Frontiers in Ecology and the Environment, 15(5), 243-247. https://doi.org/10.1002/fee.1493

Mun, J. S. C., Kabilan, B., Alagappasamy, S., \& Guha, B. (2013). Benefits of naturalistic free-ranging primate displays and implications for increased human-primate interactions. Anthrozoös, 26(1), 13-26. https://doi.org/10.2752/175303713X13534238631353

Nakamichi, M. (2007). Assessing the effects of new primate exhibits on zoo visitors' attitudes and perceptions by using three different assessment methods. Anthrozoös, 20(2), 155-165. https://doi.org/10.2752/175303707X207945

Nygren, N. V., \& Ojalammi, S. (2018). Conservation education in zoos: A literature review. Finnish Journal for Human-Animal Studies, 4, 62-76. https://doi.org/10.23984/fjhas.66540

Packer, J., \& Ballantyne, R. Motivational factors and the visitor experience: A comparison of three sites. Curator: The Museum Journal, 45(3), 183-198. https://doi.org/10.1111/j.2151-6952.2002.tb00055.x

Packer, J., Ballantyne, R., \& Luebke, J. (2018). Exploring the factors that influence zoo visitors' perceptions of the well-being of gorillas: Implications for zoo exhibit interpretation. Visitor Studies, 21(1), 57-78. https://doi.org/10.1080/10645578.2018.1503878

Palmer, C., Kasperbauer, T. J., \& Sandøe, P. (2018). Bears or butterflies? How should zoos make value-driven decisions about their collections? In B. A. Minteer, J. Maienschein, \& J. P. Collins (Eds.), The ark and beyond: The evolution of zoo and aquarium conservation (pp. 179-191). University of Chicago Press. https://doi.org/10.7208/chicago/9780226538631.003.0015

Palmer, C., \& Sandøe, P. (2016, July 8). Contributor response: How to care while conserving zoo animals. Center for Humans and Nature, Expanding our Natural \& Civic Imagination, July 2016. https://www.humansandnature.org/how-to-care-while-conserving-zoo-animals

Parker, E. N., Bramley, L., Scott, L., Marshall, A. R., Slocombe, K. E., \& Leach, M. C. (2018). An exploration into the efficacy of public warning signs: A zoo case study. PloS ONE, 13(11), 1-11. https://doi.org/10.1371/journal.pone.0207246

Pearson, E. L., Mellish, S., Sanders, B., \& Litchfield, C. (2014). Marine wildlife entanglement: Assessing knowledge, attitudes, and relevant behaviour in the Australian community. Marine Pollution Bulletin, 89(1), 136-148. https://doi.org/10.1016/j.marpolbul.2014.10.014

Philpot, P. (1996). Visitor viewing behaviour in the Gaherty reptile-breeding centre, Jersey wildlife preservation trust: a preliminary study. The Dodo: Journal of the Jersey Wildlife Preservation Trust, 32, 193-202.

Pickens, J. (2005). Attitudes and perceptions. In N. Borkowski (Ed.), Organizational behavior in health care, 3rd ed. (pp. 43-75). Jones \& Bartlett Publisher. 
Pifarré, M., Valdez, R., González-Rebeles, C., Vázquez, C., Romano, M., \& Galindo, F. (2012). The effect of zoo visitors on the behaviour and faecal cortisol of the Mexican wolf (Canis lupus baileyi). Applied Animal Behaviour Science, 136(1), 57-62. https://doi.org/10.1016/j.applanim.2011.11.015

Povey, K. D., \& Rios, J. (2002). Using interpretive animals to deliver affective messages in zoos. Journal of Interpretation Research, 7(2), 19-28. https://doi.org/10.1177/109258720200700203

Price, E. C., Ashmore, L. A., \& McGivern, A. M. (1994). Reactions of zoo visitors to free-ranging monkeys. Zoo Biology, 13(4), 355-373. https://doi.org/10.1002/zoo.1430130409

Rabb, G. B., \& Saunders, C. D. (2005). The future of zoos and aquariums: Conservation and caring. International Zoo Yearbook, 39(1), 1-26. https://doi.org/10.1111/j.1748-1090.2005.tb00001.x

Rapp, S., Vannelli, K., Castaneda, L., Beckhelling, A., Ekard, S., Hilker, C., Rose-Hinostroza, J., Sampson, A., Lloyd, M., \& Stanek, L. (2017). Communicating the conservation message-using ambassador cheetahs to connect, teach, and inspire. In L. Marker, L. Boast, \& A. Schmidt-Kuentzel (Eds.), Cheetahs: Biology and conservation (pp. 403-412). Elsevier Academic Press.

Razal, C. B., \& Miller, L. J. (2019). Examining the impact of naturalistic and unnaturalistic environmental enrichment on visitor perception of naturalness, animal welfare, and conservation. Anthrozoös, 32(1), 141153. https://doi.org/10.1080/08927936.2019.1550289

Reade, L. S., \& Waran, N. K. (1996). The modern zoo: How do people perceive zoo animals? Applied Animal Behaviour Science, 47(1-2), 109-118. https://doi.org/10.1016/0168-1591(95)01014-9

Reading, R. P., \& Miller, B. J. (2007). Attitudes and attitude change among zoo visitors. In A. Zimmermann, M. Hatchwell, L. Dickie, \& C. West (Eds.), Zoos in the 21st century: Catalysts for conservation? (pp. 63-91). Cambridge University Press.

Rhoads, D. L., \& Goldsworthy, R. J. (1979). The effects of zoo environments on public attitudes towards endangered wildlife. International Journal of Environmental Studies, 13(4), 283-287. https://doi.org/10.1080/00207237908709834

Ridgway, S. C., Livingston, M., \& Smith, S. E. (2005). Visitor behavior in zoo exhibits with underwater viewing. Visitor Studies Today, 8, 1-10.

Roe, K., \& McConney, A. (2015). Do zoo visitors come to learn? An internationally comparative, mixed-methods study. Environmental Education Research, 21(6), 865-884. https://doi.org/10.1080/13504622.2014.940282

Rose, P. E. (2018). Ensuring a good quality of life in the zoo: Underpinning welfare-positive animal management with ecological evidence. In M. Berger \& S. Corbett (Eds.), Zoo animals: Husbandry, welfare and public interactions (pp. 141-198). Nova Science.

Roth, E. K., Visscher, N. C., \& Ha, R. R. (2017). Food for thought: Assessing visitor comfort and attitudes toward carcass feeding at the ABQ BioPark Zoo. Anthrozoös, 30(2), 227-235. https://doi.org/10.1080/08927936.2017.1310987

Safina, C. (2018). Where are zoos going, or are they gone? Journal of Applied Animal Welfare Science, 21 (sup1), 411. https://doi.org/10.1080/10888705.2018.1515015

Sellinger, R. L., \& Ha, J. C. (2005). The effects of visitor density and intensity on the behavior of two captive jaguars (Panthera onca). Journal of Applied Animal Welfare Science, 8(4), 233-244. https://doi.org/10.1207/s15327604jaws0804_1

Sherwen, S. L., \& Fanson, K. V. (2015). Validation of an assay to measure glucocorticoid metabolites in the droppings of little penguins (Eudyptula minor). Journal of Zoo and Aquarium Research, 3(4), 134-136. https://doi.org/10.19227/jzar.v3i4.135

Sherwen, S. L., Harvey, T. J., Magrath, M. J. L., Butler, K. M., Fanson, K. V., \& Hemsworth, P. H. (2015). Effects of visual contact with zoo visitors on black-capped capuchin welfare. Applied Animal Behaviour Science, 167, 65-73. https://doi.org/10.1016/j.applanim.2015.03.004

Sherwen, S. L., \& Hemsworth, P. H. (2019). The visitor effect on zoo animals: Implications and opportunities for zoo animal welfare. Animals, 9(6), 366. https://doi.org/10.3390/ani9060366

Sherwen, S., Hemsworth, L., Beausoleil, N., Embury, A., \& Mellor, D. (2018). An animal welfare risk assessment process for zoos. Animals, 8(8), 130. https://doi.org/10.3390/ani8080130

Sherwen, S. L., Hemsworth, P. H., Butler, K. L., Fanson, K. V., \& Magrath, M. J. L. (2015). Impacts of visitor number on kangaroos housed in free-range exhibits. Zoo Biology, 34(4), 287-295. https://doi.org/10.1002/zoo.21226

Sherwen, S. L., Magrath, M. J. L., Butler, K. L., \& Hemsworth, P. H. (2015). Little penguins, Eudyptula minor, show increased avoidance, aggression and vigilance in response to zoo visitors. Applied Animal Behaviour Science, 168, 71-76. https://doi.org/10.1016/j.applanim.2015.04.007 
Sherwen, S. L., Magrath, M. J., Butler, K. L., Phillips, C. J., \& Hemsworth, P. H. (2014). A multi-enclosure study investigating the behavioural response of meerkats to zoo visitors. Applied Animal Behaviour Science, 156, 70-77. https://doi.org/10.1016/j.applanim.2014.04.012

Sherwood, K. P., Rallis, S. F., \& Stone, J. (1989). Effects of live animals vs. preserved specimens on student learning. Zoo Biology, 8(1), 99-104. https://doi.org/10.1002/zoo.1430080112

Shettel-Neuber, J. (1988). Second- and third-generation zoo exhibits: A comparison of visitor, staff, and animal responses. Environment and Behavior, 20(4), 452-473. https://doi.org/10.1177/0013916588204005

Skibins, J. C., \& Powell, R. B. (2013). Conservation caring: Measuring the influence of zoo visitors' connection to wildlife on pro-conservation behaviors. Zoo Biology, 32(5), 528-540. https://doi.org/10.1002/zoo.21086

Smith, L., Broad, S., \& Weiler, B. (2008). A closer examination of the impact of zoo visits on visitor behaviour. Journal of Sustainable Tourism, 16(5), 544-562. https://doi.org/10.1080/09669580802159628

Smith, L., Weiler, B., Smith, A., \& van Dijk, P. (2012). Applying visitor preference criteria to choose pro-wildlife behaviors to ask of zoo visitors. Curator: The Museum Journal, 55(4), 453-466. https://doi.org/10.1111/j.2151-6952.2012.00168.x

Spooner, S. L., Farnworth, M. J., Ward, S. J., \& Whitehouse-Tedd, K. M. (2021). Conservation education: Are zoo animals effective ambassadors and is there any cost to their welfare? Journal of Zoological and Botanical Gardens, 2(1), 41-65. https://doi.org/10.3390/jzbg2010004

Spooner, S. L., Jensen, E. A., Tracey, L., \& Marshall, A. R. (2019). Evaluating the impacts of theatre-based wildlife and conservation education at the zoo. Environmental Education Research, 25(8), 1231-1249. https://doi.org/10.1080/13504622.2019.1569201

Spooner, S. L., Jensen, E. A., Tracey, L., \& Marshall, A. R. (2021). Evaluating the effectiveness of live animal shows at delivering information to zoo audiences. International Journal of Science Education, Part B, 11(1), 1-16. https://doi.org/10.1080/21548455.2020.1851424

Stoinski, T. S., Allen, M. T., Bloomsmith, M. A., Forthman, D. L., \& Maple, T. L. (2002). Educating zoo visitors about complex environmental issues: Should we do it and how? Curator: The Museum Journal, 45(2), 129-143. https://doi.org/10.1111/j.2151-6952.2002.tb01187.x

Swanagan, J. S. (2000). Factors influencing zoo visitors' conservation attitudes and behavior. Journal of Environmental Education, 31(4), 26-31. https://doi.org/10.1080/00958960009598648

Tofield, S., Coll, R. K., Vyle, B., \& Bolstad, R. (2003). Zoos as a source of free choice learning. Research in Science and Technological Education, 21(1), 67-100. https://doi.org/10.1080/02635140308342

Tribe, A., \& Booth, R. (2003). Assessing the role of zoos in wildlife conservation. Human Dimensions of Wildlife, 8(1), 65-74. https://doi.org/10.1080/10871200390180163

Tripp, J. K. (1985). Increasing activity in captive orangutans: Provision of manipulable and edible materials. Zoo Biology, 4(3), 225-234. https://doi.org/10.1002/zoo.1430040303

Wagoner, B., \& Jensen, E. (2010). Science learning at the zoo: Evaluating children's developing understanding of animals and their habitats. Psychology and Society, 3(1), 65-76.

Wilson, M., Kelling, A., Poline, L., Bloomsmith, M., \& Maple, T. (2003). Post-occupancy evaluation of Zoo Atlanta's Giant Panda Conservation Center: Staff and visitor reactions. Zoo Biology, 22(4), 365-382. https://doi.org/10.1002/zoo.10102

Whitehouse-Tedd, K. M., Spooner, S. L., Scott, L., \& Lozano-Martinez, J. (2018). Animal ambassador encounter programmes in zoos: Current status and future research needs. In M. Berger \& S. Corbett (Eds.), Zoo animals: Husbandry, welfare and public interactions. Animal science, issues and research (pp. 89-140). Nova Science Publishers.

Whitehouse-Tedd, K., Spooner, S., \& Whitehouse-Tedd, G. (2020). Making training educational for zoo visitors. In V. A. Melfi, N. R. Dorey, \& S. J. Ward (Eds.), Zoo animal learning and training (pp. 249-269). WileyBlackwell. https://doi.org/10.1002/9781118968543.ch10

Whitworth, A. W. (2012). An investigation into the determining factors of zoo visitor attendances in UK zoos. PLoS ONE, 7(1), e29839. https://doi.org/10.1371/journal.pone.0029839

Wolf, R. L., \& Tymitz, B. L. (1981). Studying visitor perceptions of zoo environments: A naturalistic view. International Zoo Yearbook, 21(1), 49-53. https://doi.org/10.1111/j.1748-1090.1981.tb01943.x

Wood, W. (1998). Interactions among environmental enrichment, viewing crowds, and zoo chimpanzees (Pan troglodytes). Zoo Biology, 17(3), 211-230. https://doi.org/10.1002/(SICI)10982361(1998)17:3\%3C211::AID-ZOO5\%3E3.0.CO;2-C

World Association of Zoos and Aquariums (WAZA). (2005). Building a future for wildlife: The World Zoo and Aquarium conservation strategy. https://www.waza.org/wp-content/uploads/2019/03/wzacs-en.pdf 
World Association of Zoos and Aquariums (WAZA). (2020). WAZA guidelines for animal-visitor interactions. https://www.waza.org/wp-content/uploads/2020/05/ ENG_WAZA-Guidelines-for-AVI_FINAL_April2020.pdf

Wyles, K. J., Pahl, S., White, M., Morris, S., Cracknell, D., \& Thompson, R. C. (2013). Towards a marine mindset: Visiting an aquarium can improve attitudes and intentions regarding marine sustainability. Visitor Studies, 16(1), 95-110. https://doi.org/10.1080/10645578.2013.768077

Yalowitz, S. S. (2004). Evaluating visitor conservation research at the Monterey Bay aquarium. Curator: The Museum Journal, 47(3), 283-298. https://doi.org/10.1111/j.2151-6952.2004.tb00126.x

Yilmaz, S., Düzenli, T., \& Çiğdem, A. (2017). Visitor experiences in different zoo exhibits. Current World Environment, 12(1), 17-27. https://doi.org/10.12944/CWE.12.1.03

Yilmaz, S., Mumcu, S., \& Özbilen, A. (2010). Effects of spatial differences on visitor perceptions at zoo exhibits. Scientific Research and Essays, 5(16), 2327-2340. 